\title{
PENGARUH APE BOWLING HURUF HIJAIYYAH TERHADAP KEMAMPUAN MENGENAL HURUF HIJAIYYAH ANAK USIA DINI
}

\author{
Siti Labiba Kusna ${ }^{\text {a, } 1}$, Maratus Shalikah ${ }^{\text {b, } 2}$ \\ ${ }^{\text {a }}$ Universitas NU Sunan Giri Bojonegoro, Indonesia \\ ${ }^{1}$ sitilabibaku@sunan-giri.ac.id, ${ }^{2}$ maratusshalikah@gmail.com
}

\author{
Informasi artikel \\ Received: \\ September 7, 2021. \\ Revised : \\ September 14,2021 \\ Publish : \\ September 23,2021
}

Kata kunci:

Alat Permainan

Edukatif;

Bowling Huruf

Hijaiyyah;

Mengenal Huruf.

Keywords:

Educational Game

Tools;

Bowling Hijaiyyah

Letters; Recogniz-

ing Letter.

\begin{abstract}
ABSTRAK
Penelitian ini bertujuan untuk mengetahui pengaruh dari alat permainan edukatif bowling huruf hijaiyyah terhadap kemampuan mengenal huruf hijaiyyah anak usia 4-5 tahun di RA Al-Makmur Mayangrejo Kecamatan Kalitidu Bojonegoro. Penelitian ini menggunakan jenis penelitian kuantitatif dengan pendekatan eksperimen. Yang menjadi subyek dalam penelitian ini adalah seluruh anak kelompok A di RA Al-Makmur yang berjumlah 15 anak. Pengumpulan data dilakukan dengan teknik wawancara, observasi dan dokumentasi. Teknik analisis data pada penelitian ini dengan uji statistika dan mendeskripsikan data. Hasil penelitian dan uji hipotesis telah menunjukkan bahwa hasil pencapaian perkembangan anak dalam mengenal huruf hijaiyyah mengalami kenaikan, sehingga alat permainan edukatif bowling huruf hijaiyyah berpengaruh terhadap perkembangan kognitif yang lebih baik, yaitu anak mampu mengenal huruf hijaiyyah. Analisis deskriptif yang diperoleh dari hasil uji sign wilcoxon dapat diketahui bahwa nilai Asymp. Sig. $<0,05$, sehingga dapat disimpulkan bahwa Ho ditolak dan Ha diterima. Jadi, terdapat pengaruh perkembangan kemampuan mengenal huruf hijaiyyah yang signifikan antara sebelum dan sesudah penggunaan alat permainan edukatif bowling huruf hijaiyyah. Peningkatan tersebut menunjukkan bahwa alat permainan edukatif bowling huruf hijaiyyah berpengaruh terhadap kemampuan mengenal huruf hijaiyyah anak usia 4-5 tahun
\end{abstract}

ABSTRACT
This study aims to determine the effect of the bowling hijaiyyah educational
game tool on the ability to recognize hijaiyyah letters for children aged 4-5
years at RA Al-Makmur Mayangrejo, Kalitidu District, Bojonegoro. This
research uses quantitative research with an experimental approach. The sub-
jects in this study were all 15 children of group A in RA Al-Makmur. Data
was collected by using interview, observation and documentation tech-
niques. The data analysis technique in this study was statistical tests and de-
scribed the data. The results of research and hypothesis testing have shown
that the achievement of children's development in recognizing hijaiyyah let-
ters has increased, so that the hijaiyyah bowling educational game tool has
an effect on better cognitive development, namely children are able to rec-
ognize hijaiyyah letters. Descriptive analysis obtained from the results of the
Wilcoxon sign test can be seen that the Asymp value. Sig. <0.05, so it can
be concluded that Ho is rejected and Ha is accepted. So, there is a significant
influence on the development of the ability to recognize hijaiyyah letters be-
tween before and after the use of the hijaiyyah bowling educational game
tool. This increase shows that the bowling hijaiyyah educational game tool
affects the ability to recognize hijaiyyah letters for children aged $4-5$ years.

This work is licensed under a Creative Commons Attribution-ShareAlike 4.0 International Li-

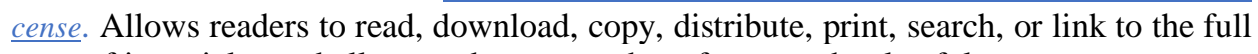
texts of its articles and allow readers to use them for any other lawful purpose. 


\section{PENDAHULUAN}

Anak usia dini merupakan individu yang sedang mengalami pertumbuhan dan perkembangan secara pesat, sehingga masa ini disebut masa keemasan (golden age), atau suatu masa yang menjadi dasar dan memberi pengaruh besar terhadap kualitas perkembangan anak selanjutnya. Pada masa golden age semua aspek perkembangan anak dapat dengan mudah distimulasi dan hanya berlangsung satu kali sepanjang rentang kehidupan manusia. Upaya pengembangan menyeluruh yang melibatkan aspek pengasuhan, kesehatan, pendidikan dan perlindungan perlu dilakukan.

Menurut (Santrock dalam Widodo, 2013) bahwa anak pada masa usia dini merupakan momen penting dalam perkembangan otak, kecerdasan dan kemampuan belajar anak yang signifikan. Anak usia dini sangat membutuhkan stimulasi dan rangsangan dari lingkungannya untuk dapat mengembangkan berbagai potensi yang dimilikinya.

Undang Undang Nomor 20 Tahun 2003 tentang Sistem Pendidikan Nasional Bab I Pasal 1 butir 14 menyatakan bahwa PAUD merupakan suatu upaya pembinaan yang ditujukan kepada anak sejak lahir sampai dengan usia 6 tahun yang dilakukan melalui rangsangan pendidikan untuk membantu pertumbuhan dan perkembangan jasmani dan rohani agar anak memiliki kesiapan belajar dalam memasuki pendidikan lebih lanjut. Undang-undang ini mengamanatkan bahwa pendidikan harus dipersiapkan secara terencana dan bersifat holistik sebagai dasar anak memasuki pendidikan lebih lanjut. Pendidikan Anak Usia Dini (PAUD) pada pendidikan formal meliputi Taman Kanak-Kanak (TK), Raudhatul Athfal (RA), atau lembaga lain yang sederajat. PAUD jalur nonformal meliputi Kelompok Bermain (KB), Taman Penitipan Anak (TPA), atau lembaga lain yang sederajat. PAUD jalur informal meliputi pendidikan dalam keluarga atau yang diselenggarakan oleh lingkungan.

Pembelajaran pada anak usia dini hendaknya menyenangkan dan tidak membosankan. Banyak orang tua dan guru berlomba dengan waktu untuk memberikan pengalaman belajar melalui kegiatan atau pembelajaran akademik. Hampir keseluruhan waktu belajar anak dilakukan melalui kegiatan akademik. Anak duduk diam di kursi masing-masing untuk mendengarkan, menulis atau mengerjakan lembar/buku 
kerja anak. Sedikit sekali kegiatan belajar dilakukan dalam bentuk bermain. Akibatnya, kebutuhan dasar bermain yang berkaitan dengan kegiatan perkembangan emosi, sosial, bahasa, dan seni belum maksimal terpenuhi.

Bermain mempunyai makna penting bagi pertumbuhan anak. Bermain merupakan pekerjaan masa kanak-kanak dan cermin pertumbuhan anak (Gordon \& Browne, 1985). Bermain merupakan kegiatan yang memberikan kesenangan dan dilaksanakan untuk kegiatan itu sendiri, yang lebih ditekankan pada cara daripada hasil yang diperoleh dari kegiatan tersebut ( Dworetsky, 1990 ). Menurut Dearden (Hetherington \& Parke, 1999 ) bermain merupakan kegiatan yang tidak terlalu mengikat dan segalanya ada dalam kegiatan itu sendiri, yang dapat memberikan kepuasan bagi anak. Bermain berarti berlatih, mengeksploitasi, merekayasa, mengulang latihan apapun yang dapat dilakukan untuk mentransformasi secara imajinatif hal-hal yang sama dengan dunia orang dewasa (Hildebrand, 1996).

Menurut (Vygotsky dalam Khadijah 2016) berpendapat bahwa kegiatan bermain secara langsung berperan dalam berbagai usaha pengembangan kognitif anak. Menurut Bruner bahwa bermain mendorong anak melakukan berbagai kegiatan dalam memecahkan berbagai masalah melalui penemuan. Menurut Al Ghazali bermain-main bagi seorang anak adalah sesuatu yang sangat penting. Sebab, melarangnya bermainmain seraya memaksakan untuk belajar terus menerus dapat mematikan hatinya, mengganggu kecerdasannya, dan merusak irama hidupnya.

Berdasarkan pendapat para ahli tersebut maka bermain sangat penting bagi anak usia dini karena melalui bermain dapat mengembangkan aspek-aspek perkembangan anak, ialah aspek fisik, sosial emosional dan kognitif. Kegiatan bermain juga merupakan wahana bagi anak dalam melakukan berbagai eksperimen tentang berbagai konsep yang diketahui dan yang belum diketahuinya.

Hasil observasi di RA Al-Makmur Mayangrejo Kecamatan Kalitidu Bojonegoro, tepatnya di kelas A (usia 4-5 tahun) telah ditemukan 7 anak dari 15 anak yang mengalami kesulitan dalam mengenal dan memahami huruf hijaiyyah. 7 anak tersebut masih kesulitan dalam menghafalkan bunyi dan tulisan hurufnya. Padahal kemampuan mengenal huruf hijaiyyah merupakan kemampuan dasar yang diperlukan untuk tahapan menghafal huruf hijaiyyah selanjutnya. Diperoleh pula hasil wawancara kepada seorang guru di kelas tersebut (Nurul Hamidah, S.Pd.) bahwa kegiatan 
pembelajaran di kelas seringkali terjadi kendala pada anak- anak dalam memahami materi yang disampaikan gurunya. Hal ini dimungkinkan karena faktor usia anak yang masih terlalu dini serta kejenuhan yang dialami oleh anak-anak membuat mereka malas untuk belajar. Anak-anak merasa bosan belajar karena metode belajar yang digunakan kurang menarik. Anak cenderung banyak bermain dengan teman-temannya dibandingkan dengan mendengarkan gurunya, dan berlari-lari dengan temannya (24 November 2018, 08.00 WIB).

Huruf Hijaiyyah atau huruf Arab yaitu huruf yang dipergunakan dalam penulisan kitab suci Al-Quran. Dalam pembelajaran huruf Arab memang tidak begitu mudah, apalagi untuk anak-anak. Juga banyak orang tua yang kesulitan memperkenalkan huruf hijaiyyah pada anak-anaknya. Bahkan, bukan tidak mungkin masih ada orang tua dari anak-anak tersebut yang tidak tahu banyak tentang huruf hijaiyyah. Dalam pengenalan huruf hijaiyyah kepada anak-anak ini harus dengan metode yang menarik perhatian.

Pengenalan huruf hijaiyyah pada anak usia dini sangatlah penting, karena merupakan landasan dalam membaca Al-Qur'an sebagai pedoman hidup umat Islam. Pada masa ini anak lebih mudah untuk memahami dan merekam sesuatu di otak atau memorinya, dibandingkan di usia tua atau dewasa. Pengenalan huruf hijaiyyah pada anak-anak memerlukan metode pembelajaran yang efektif dan menyenangkan, agar anak tidak merasa bosan sehingga anak tetap fokus pada materi pembelajaran. Dengan demikian, suatu tujuan pembelajaran akan tercapai dengan baik

Pentingnya arti bermain bagi anak mendorong peneliti untuk menciptakan sebuah alat permainan edukatif yang sederhana dan diharapkan mampu meningkatkan kemampuan anak dalam mengenal huruf hijaiyyah. Menurut Suryadi (2007), bahwa alat permainan edukatif merupakan alat yang sengaja dirancang khusus sebagai alat untuk membantu proses pembelajaran dan dapat mengoptimalkan perkembangan anak, disesuaikan dengan usia dan tingkat perkembangannya. Anak usia dini membutuhkan permainan sebagai media pendidikan dalam proses pembelajaran. Alat bermain tidak harus mahal, unsur mendidiklah yang harus diutamakan. Lebih jelas lagi jika menyampaikan materi pembelajaran dengan pendekatan belajar sambil bermain. (Andang, 2006). 
Permainan-permainan edukatif dapat diciptakan dengan membuat alat permainan yang memiliki sifat-sifat, seperti bongkar-pasang, pengelompokan, memadukan, mencari padanan, merangkai, membentuk, mengetok, menyusun, dan lain sebagainya. Menurut (Burnett dalam Harun, 2008) menyatakan bahwa mengenal huruf merupakan hal penting bagi anak usia dini yang didengar dari lingkungannya baik huruf latin, huruf Arab dan lainnya. Berbagai huruf yang dikenal anak menumbuhkan kemampuan untuk memilih dan memilah berbagai jenis huruf. Melatih anak untuk mengenal huruf dan mengucapkannya mesti harus diulang-ulang. Alat permainan edukatif bowling huruf hijaiyyah adalah suatu APE yang sederhana dan menarik. Bahan-bahannya bisa didapat dengan mudah karena dapat menggunakan bahan-bahan bekas di sekitar kita. Cara bermainnya mudah dipahami dan dilakukan oleh anak-anak. Selain untuk melatih ketepatan gerak, koordinasi mata-tangan, dan motorik kasar, APE ini juga mampu melatih anak untuk lebih mudah mengenal huruf hijaiyyah

Berdasarkan uraian di atas, penulis tertarik untuk melakukan penelitian di RA Al-Makmur Mayangrejo Kecamatan Kalitidu khususnya di kelas A (4-5 tahun). Dengan melalui APE Bowling Huruf Hijaiyyah ini diharapkan mampu membantu lebih meningkatnya semangat dan kemampuan anak-anak dalam mengenal huruf hijaiyyah.

\section{METODE}

Metode penelitian yang digunakan adalah metode penelitian kuantitatif dengan pendekatan eksperimen. Desain penelitian yang akan digunakan dalam penelitian ini yakni One Group Pretest-Posttest Design. Struktur desainnya adalah sebagai berikut :

$$
\begin{aligned}
& \text { O1 X } \\
& \text { O2 }
\end{aligned}
$$

\section{Desain penelitian One Group Pretest-Posttest Design}

Di mana sebelum eksperimen (O1) di sebut pretest, yakni kemampuan anak usia 4-5 tahun dalam mengenal huruf hijaiyyah sebelum menggunakan alat permainan edukatif bowling huruf hijaiyyah, dan sesudah eksperimen (O2) disebut posttest, 
yakni kemampuan anak usia 4-5 tahun dalam mengenal huruf hijaiyyah sesudah menggunakan alat permainan edukatif bowling huruf hijaiyyah.

Populasi pada penelitian ini adalah seluruh anak kelompok A (4-5 tahun) di RA Al-Makmur Mayangrejo Kecamatan Kalitidu Bojonegoro, yakni 15 anak. Dikarenakan jumlah populasi kurang dari 100, maka seluruh anggota populasi dijadikan sampel dengan teknik sampling jenuh, atau teknik penentuan sampel yang menjadikan semua anggota populasi sebagai sampel, dengan syarat populasi yang ada kurang dari 30 orang. Teknik pengumpulan data menggunakan observasi, wawancara dan dokumentasi.

Teknik analisis data statistik yang akan digunakan dalam penelitian ini adalah Uji Validitas, Uji Relialibilitas dan Uji Hipotesis, dalam uji hipotesis Perbedaan pengisian lembar observasi pada saat pretest dan posttest kelompok eksperimen digunakan teknik analisis data uji wilcoxon signed ranks test. Uji Wilcoxon signed ranks test merupakan salah satu uji teknik nonparametrik untuk mengukur signifikansi perbedaan antara dua kelompok data berpasangan.

Adapun syarat-syarat penggunaan uji Wilcoxon signed ranks test, sebagai berikut:

a. Jumlah sampel penelitian sedikit, kurang dari 30 sampel.

b. Digunakan data berpasangan dengan skala ordinal atau interval.

Untuk dasar pengambilan keputusan uji wilcoxon signed ranks test, sebagai berikut:

a. Jika nilai Asymp. Sig. (2-tailed) lebih kecil dari < 0.05, maka Ha diterima.

b. Jika nilai Asymp. Sig. (2-tailed) lebih besar dari > 0.05, maka Ha ditolak.

Teknik analisis data hitung ini dengan menggunakan bantuan IBM SPSS Statistics versi 20 for windows.

\section{PEMBAHASAN}

Alat permainan edukatif bowling huruf hijaiyyah ini digunakan peneliti sebagai sarana untuk melakukan pembelajaran agar tercapai secara optimal, yakni pembelajaran pengenalan huruf hijaiyyah

\section{Uji validitas dan Relibialitas}

Hasil uji validitas instrumen penelitian dapat diketahui bahwa seluruh item instrumen pada variabel perkembangan kemampuan mengenal huruf hijaiyyah memiliki nilai $r$ hitung antara $0,902-0,976>$ dari $r$ tabel 0,632 yang diperoleh dari $(n-2) 10$ 
sampel, sehingga dapat disimpulkan bahwa seluruh item instrumen penelitian pada variabel perkembangan kemampuan mengenal huruf hijaiyyah dinyatakan valid.

Hasil uji reliabilitas instrumen penelitian dapat diketahui bahwa nilai alpha cronbach pada variabel kognitif anak sebesar 0,966, dinyatakan reliabel karena memiliki nilai di atas 0,6 .

\section{Pretes}

Pengambilan data pretest dilakukan pada subyek penelitian sebanyak satu kali. Pelaksanaan pretest dilakukan pada tanggal 31 Mei dan 1 Juni 2019, mulai pukul 08.00 sampai dengan 09.00, selama 60 menit bertempat di ruang kelas A RA AlMakmur Mayangrejo Kecamatan Kalitidu Bojonegoro. Tes tersebut digunakan untuk memperoleh data awal mengenai kemampuan mengenal huruf hijaiyyah pada anak sebelum diberikan pembelajaran dengan alat permainan edukatif bowling huruf hijaiyyah

Analisis Deskriptif Pretest Kemampuan Mengenal Huruf Hijaiyyah

\begin{tabular}{|c|l|l|c|c|}
\hline No. & Rentang Skor & \multicolumn{1}{|c|}{ Kategori } & Jumlah & Presentase \\
\hline 1. & $6-12$ & Kurang & 7 & $46,6 \%$ \\
\hline 2. & $13-18$ & Cukup & 4 & $26,6 \%$ \\
\hline 3. & $19-23$ & Baik & 4 & $26,6 \%$ \\
\hline 4. & 24 & Sangat baik & 0 & $0 \%$ \\
\hline \multicolumn{4}{|c|}{ Nilai rata-rata } & 13,93 \\
\hline \multicolumn{4}{|c|}{ Nilai tertinggi } & 22 \\
\hline \multicolumn{4}{|c|}{ Nilai terendah } \\
\hline
\end{tabular}

Berdasarkan tabel 4.6 dapat diketahui bahwa perkembangan kemampuan dalam mengenal huruf hijaiyyah dapat dibagi menjadi 4 kategori, yaitu kategori kurang, cukup, baik dan sangat baik. Pada anak yang mendapatkan rentang skor 6-12 dengan kategori kurang berjumlah 7 anak atau 46,6\%. Pada anak yang mendapatkan rentang skor 13-18 dengan kategori cukup berjumlah 4 anak atau 26,6\%. Kemudian, pada anak yang mendapatkan rentang skor 19-23 dengan kategori baik berjumlah 4 anak atau 26,6\%. Dan pada anak yang mendapatkan rentang skor 24 dengan kategori sangat baik berjumlah 0 anak atau $0 \%$. Sehungga dapat disimpulkan bahwa perkembangan kemampuan anak-anak dalam mengenal huruf hijaiyyah mayoritas pada 13-18 yaitu pada kategori cukup. 


\section{Treatmen}

Perlakuan berlangsung selama 4 hari, yaitu pada tanggal 14-15 Juni dan 2122 Juni 2019. Pelaksanaan treatment dilakukan mulai pukul 08.00 sampai dengan 09.00, berlangsung selama 60 menit dan bertempat di ruang kelas A RA Al- Makmur Mayangrejo Kecamatan Kalitidu Bojonegoro. Tes tersebut digunakan untuk memperoleh data anak pada saat diberikan pembelajaran mengenai pengenalan huruf hijaiyyah menggunakan alat permainan edukatif bowling huruf hijaiyyah. Treatment dilaksanakan secara bergiliran/satu per satu. Treatment dilakukan oleh seluruh anak kelompok A (15 anak) dengan melakukan permainan bowling huruf hijaiyyah.

\section{Posttes}

Pengambilan data posttest dilakukan pada subyek penelitian sebanyak satu kali. Pelaksanaan posttest dilakukan pada tanggal 21-22 Juni 2019, mulai pukul 08.00 sampai dengan 09.00, selama 60 menit bertempat di ruang kelas A RA AlMakmur Mayangrejo Kecamatan Kalitidu Bojonegoro. Tes tersebut digunakan untuk memperoleh data mengenai kemampuan mengenal huruf hijaiyyah pada anak sesudah diberikan pembelajaran dengan alat permainan edukatif bowling huruf hijaiyyah. Pengambilan data posttest dengan menggunakan instrumen penelitian berupa lembar observasi yang telah disusun secara terperinci serta dengan menggunakan skor, Peneliti tinggal memberikan skor pada kriteria yang sesuai.

Analisis Deskriptif Posttest Kemampuan Mengenal Huruf Hijaiyyah

\begin{tabular}{|c|c|c|c|c|}
\hline No. & Rentang Skor & Kategori & Jumlah & Presentase \\
\hline 1. & $6-12$ & Kurang & 2 & $13,33 \%$ \\
\hline 2. & $13-18$ & Cukup & 6 & $40 \%$ \\
\hline 3. & $19-23$ & Baik & 7 & $46,66 \%$ \\
\hline 4. & 24 & Sangat baik & 0 & $0 \%$ \\
\hline \multicolumn{4}{|c|}{ Nilai rata-rata } & 18,06 \\
\hline \multicolumn{4}{|c|}{ Nilai tertinggi } & 23 \\
\hline \multicolumn{4}{|c|}{ Nilai terendah } & 12 \\
\hline
\end{tabular}

Berdasarkan tabel diatas dapat diketahui bahwa perkembangan kemampuan dalam mengenal huruf hijaiyyah dapat dibagi menjadi 4 kategori, yaitu kategori kurang, cukup, baik dan sangat baik. Pada anak yang mendapatkan rentang skor 6-12 dengan kategori kurang berjumlah 2 anak atau 13,33\%. Pada anak yang mendapatkan rentang skor 13-18 dengan kategori cukup berjumlah 6 anak atau 40\%. Kemudian, 
pada anak yang mendapatkan rentang skor 19-23 dengan kategori baik berjumlah 7 anak atau 46,66\%. Dan pada anak yang mendapatkan rentang skor 24 dengan kategori sangat baik berjumlah 0 anak atau 0\%. Sehungga dapat disimpulkan bahwa perkembangan kemampuan anak-anak dalam mengenal huruf hijaiyyah mayoritas pada 13-18 yaitu pada kategori cukup.

\section{Uji hipotesis}

Uji perbandingan perbedaan antara sebelum perlakuan (pretest) dengan sesudah perlakuan (posttest) penerapan alat permainan edukatif bowling huruf hijaiyyah terhadap kemampuan mengenal huruf hijaiyyah dalam penelitian ini, dengan menggunakan uji sign wilcoxon. Dasar pengambilan keputusan uji sign wilcoxon, sebagai berikut:

a) Jika nilai Asymp. Sig. (2-tailed) lebih kecil dari $<0.05$, maka $\mathrm{Ha}$ diterima.

b) Jika nilai Asymp. Sig. (2-tailed) lebih besar dari > 0.05, maka Ha ditolak Adapun hasil uji sign wilcoxon, sebagai berikut:

\begin{tabular}{|l|l|}
\hline Test Statistics $^{\text {a }}$ \\
\hline & posttest - pretest \\
\hline$Z$ & $-3,420^{\mathrm{b}}$ \\
\hline Asymp. Sig. (2-tailed) &, 001 \\
\hline
\end{tabular}

Hasil Uji Sign Wilcoxon

a. Wilcoxon Signed Ranks Test

b. Based on negative ranks.

Berdasarkan hasil uji sign wilcoxon di atas dapat diketahui bahwa nilai Asymp. Sig. ialah 0,001. Nilai Asymp. Sig. < 0,05, sehingga dapat disimpulkan bahwa Ho ditolak dan Ha diterima. Jadi, terdapat pengaruh perkembangan kemampuan mengenal huruf hijaiyyah yang signifikan antara sebelum dan sesudah penggunaan alat permainan edukatif bowling huruf hijaiyyah.

\section{KESIMPULAN}

Penggunaan alat permainan edukatif bowling huruf hijaiyyah efektif terhadap kemampuan mengenal huruf hijaiyyah pada anak usia 4-5 tahun di RA Al-Makmur Mayangrejo Kecamatan Kalitidu Bojonegoro. Analisis deskriptif 
yang diperoleh dari hasil uji sign wilcoxon dapat diketahui bahwa nilai Asymp. Sig. < 0,05, sehingga dapat disimpulkan bahwa Ho ditolak dan Ha diterima. Jadi, terdapat pengaruh perkembangan kemampuan mengenal huruf hijaiyyah yang signifikan antara sebelum dan sesudah penggunaan alat permainan edukatif bowling huruf hijaiyyah. Hal ini menunjukkan bahwa hasil pencapaian perkembangan anak dalam mengenal huruf hijaiyyah mengalami kenaikan, alat permainan edukatif bowling huruf hijaiyyah memiliki pengaruh terhadap perkembangan kognitif yang lebih baik, yaitu anak mampu mengenal huruf hijaiyyah.

\section{REFERENSI}

Arikunto, Suharsimi. 2010. Prosedur Penelitian Suatu Pendekatan Praktik. Jakarta: PT. Rineka Cipta.

Dimyati, Johni. 2014. Metodologi Penelitian Pendidikan \& Aplikasinya pada Pendidikan Anak Usia Dini (PAUD). Jakarta: Kencana Prenada Media Group

Furchan, Arief. 2005. Pengantar Penelitian Dalam Pendidikan. Yogyakarta: Pustaka Pelajar.

Hartoyo, Bambang. 2004. Konsep Dasar Pendidikan Anak Usia Dini. Jawa Tengah: Materi Tutor dan Pengelola Pendidikan Anak Usia Dini BPPLSP Regional III

Hasan, Purwakania. 2006. Psikologi Perkembangan Islami. Jakarta: Rajawali Press.

Hurlock, Elizabet B. Psikologi Perkembangan: Suatu Pendekatan Sepanjang Rentang Kehidupan.

Husain, Abd. Karim. Seni Kaligrafi Khat Naskhi. 1988. Tuntunan Menulis Halus

Huruf Arab dengan Metode Komparatif. Jakarta: Pedoman Ilmu Jaya. Iqromah,

Fitri. 2018. Identifikasi Kemampuan Anak Dalam Mengenal Huruf Hijaiyah. Jurnal Pendidikan Anak Usia Dini Edisi 1 Tahun ke 7.

Isjoni. 2011. Model Pembelajaran Anak Usia Dini. Bandung: Alfabeta.

Ismail, Andang. 2006. Education Games: Menjadi Cerdas dan Ceria dengan Permainan Edukatif. Yogyakarta: Pilar Media.

Khadijah. 2016. Pengembangan Kognitif Anak Usia Dini. Medan : Perdana Mulya Sarana.

Khairi, Husnuzziadatul. 2018. "Karakteristik Perkembangan Anak Usia Dini dari 06 Tahun" dalam Jurnal Warna Vol. 2 , No. 2.

Kusumaningtyas, Nila. 2014. Alat Perminan Edukatif Untuk Anak Usia Dini. Karawang: Delacita.

Mansur. 2009. Pendidikan Anak Usia Dini Dalam Islam. Yogyakarta: Pustaka Pelajar.

Murniningsih. 2012. Pengenalan Huruf Hijaiyyah pada Anak Usia Dini.

Mussen, Paul Henry, dkk. 1994. Perkembangn dan Kepribadian Anak, Terjemahan F.X. Budiyanto, Gianto Widianto, Arum Gayatri, Arcan.

Notoatmodjo, Soekidjo. 2005. Metodologi Penelitian Kesehatan. Jakarta: Rineka Cipta. 
Permendikbud No. 146 tahun 2014.

Purnamasari, Ariavita. 2005. Kamus Perkembangan Bayi \& Balita, Jakarta: Erlangga.

Rahman, Shofiatun A. 2010. Alat Permainan Edukatif Untuk Program PAUD, Palu: Tadulako University Press.

Rasyid, Harun, dkk. 2009. Asesmen Perkembangan Anak Usia Dini. Yogyakarta : Multi Pressindo.

Rita Rosmalia, Rita, dkk. Metode dan Evaluasi Pengembangan Kognitif.

Santrock , John W. 1995. Life Span Development: Perkembangan Masa Hidup, Jakarta: Erlangga

Sugiyono. 2010. Statistik untuk Pendidikan. Bandung: Alfabeta.

Sugiyono. 2016. Metode Penelitian Kuantitatif, Kualitatif, dan R\&D. Bandung: Alfabeta.

Sujiono, Y. Nurani. 2009. Konsep Dasar Pendidikan Anak Usia Dini. Jakarta: PT. INDEKS.

Sukardi. 2014. Metodologi Penelitian Pendidikan. Jakarta: PT Bumi Aksara. Sumanto. 1995. Metodologi Penelitian Sosial dan Pendidikan. Yogyakarta: Andi Offiset.

Suryabrata, Sumadi. 1987. Metode Penelitian. Jakarta: Rajawali.

Susanto, Ahmad. 2011. Perkembangan Anak Usia Dini. Jakarta: Kencana Prenada Media Group.

Suyadi. 2009. Psikologi Belajar Anak Usia Dini. Yogyakarta: Pedagogja. Trihendra,

Cornelius.2005. Statistik Inferen Teori Dasar \& Aplikasinya Menggunakan SPSS 12. Jogjakarta: Andi Offset, 2005.

Wibowo, Agus. 2013. Pendidikan Karakter Usia Dini. Yogyakarta: Pustaka Belajar.

Yunanto, Anjrah Herry. 2013. Penerapan Metode Bermain Bowling Aritmatika Untuk Mengembangkan Kemampuan Kognitif. Skripsi Sarjana Strata Satu (S1), Ilmu Pendidikan Prodi PG PAUD Universitas Negeri Semarang.

Yus, Anita. 2012. Model Pendidikan Anak Uisia Dini. Jakarta: Prenada Media Group. 